\title{
ARTICLE Effects of location within the tree canopy on carbohydrates, organic acids, amino acids and phenolic compounds in the fruit peel and flesh from three apple (Malus $\times$ domestica) cultivars
}

\author{
Fengjuan Feng ${ }^{1,2, *}$, Mingjun $\mathrm{Li}^{1,3, *}$, Fengwang $\mathrm{Ma}^{3}$, and Lailiang Cheng ${ }^{1}$
}

Fruits from three cultivars of apple (Malus $\times$ domestica Borkh.)—'Mclntosh', 'Gala' and 'Mutsu'—were harvested from the exterior and interior of the tree canopy. Peel and flesh tissues were sampled separately to determine how the position of the fruit on the tree might affect the levels of the primary and secondary metabolites in the fruit. Fruit from the outer-canopy had a higher fresh weight and a higher soluble solids content compared with inner-canopy fruit. Both the flesh and peel of the outer-canopy fruit had higher concentrations of soluble sugars and sugar alcohols, but lower starch concentrations than the inner-canopy fruit. Canopy position did not significantly affect malic acid concentrations, except in the peel of 'Mclntosh' and the flesh of 'Mutsu'. Although levels of ascorbic and succinic acids were higher in the peel of the outer-canopy fruit, the responses of other organic acids to canopy position depended on tissue type and cultivar. Except for histidine, lysine, threonine and glycine, most amino acids accumulated at higher concentrations in the inner-canopy fruit. By contrast, levels of phenolic compounds from both the peel and flesh were significantly higher in the outer-canopy fruit. The significant effects of location within the canopy on both primary metabolites and secondary metabolites demonstrate the importance of light exposure on apple fruit quality.

Horticulture Research (2014) 1, 14019; doi:10.1038/hortres.2014.19; Published online: 23 April 2014

\section{INTRODUCTION}

Apples are a temperate zone fruit, but they are consumed worldwide due to their unique characteristics, including color, flavor and aroma, freshness and crispness, and nutritional value. ${ }^{1,2}$ Their primary and secondary metabolites include carbohydrates, organic acids, amino acids and phenolic compounds. Carbohydrates influence crop quality and yield and determine the sweetness of this fleshy fruit at harvest time. ${ }^{3}$ Fructose, sucrose and glucose are the major soluble sugars in apples, and sorbitol is a main sugar alcohol. ${ }^{4}$ Malic acid is primarily responsible for fruit acidity in apples. ${ }^{5}$ Apples contain $90 \%$ of all available amino acids, including aspartic acid (Asp), glutamic acid (Glu), asparagine (Asn), serine (Ser) and glutamine (Gln); plus smaller quantities of glycine (Gly), threonine (Thr), $\gamma$-aminobutyric acid, phenylalanine (Phe), isoleucine (lle), leucine (Leu), ornithine (Orn), alanine (Ala), lysine (Lys), histidine (His), homoserine (Hse) and arginine (Arg). ${ }^{6,7}$ Polyphenolic compounds in apples include phenolic acids (mainly chlorogenic acid), flavanols (catechin, epicatechin and procyanidins), flavonols (quercetin glycosides), dihydrochalcones (phloridzin) and anthocyanins (cyanidin glycosides). ${ }^{8,9}$ The specific constituents and levels of metabolites vary by genotype ${ }^{10}$ and are also unevenly distributed among individual fruits. ${ }^{11,12}$ In general, the apple peel has a greater amount of phenolic compounds than the flesh, ${ }^{13,14}$ while the flesh has a higher level of chlorogenic acid. ${ }^{15}$ Phloridzin is concentrated in the seeds. ${ }^{16}$

The location within a tree canopy influences the microclimate around individual fruits, which may lead to considerable variation in their external and internal qualities. ${ }^{17-21}$ Jakopic et al. ${ }^{22}$ have reported that in 'Fuji' apple trees, the average level of photosynthetically active radiation is the lowest in the interior and lower portions of the canopy. Drogoudi and Pantelidis ${ }^{23}$ collected fruit from two sides of the upper, middle and lower portions of linearshaped canopies. In their examination of four apple cultivars, they found that the total soluble solids content and total phenolic compounds, but not flesh firmness, are greater in fruits that are exposed to more sunlight. The upper-canopy position is also associated with higher antioxidant contents in the peel of all cultivars except 'Fyriki' and in the flesh of 'Fuji Kiku 8' and 'Imperial Double Red Delicious'. Nilsson and Gustavsson ${ }^{24}$ have reported that fruit that grows along the outer branches of 'Aroma' apple trees has more dry matter, soluble solids and soluble sugars, but a somewhat lower titratable acidity than fruit from the interior. By contrast, Krishnaprakash et al. ${ }^{19}$ have shown that fruit from the top of the tree has a lower mean score for juiciness, aroma, taste and soluble solids, but does not differ significantly in its acidity from fruit measured at other positions of the tree. Moreover, the coloration of some apple cultivars, such as 'Gala', is highly dependent on the location in the canopy: higher light levels lead to better color. In other cultivars, such as 'Braeburn' and 'Fuji', however, the relationship is much weaker. ${ }^{25}$ During post-harvest irradiation with ultraviolet-B-visible light, shade-grown 'Aroma' apples have a much greater potential to accumulate anthocyanins and quercetin glycosides than fruits collected from the sun-exposed side of a tree. ${ }^{26}$ These positional effects on fruit quality characteristics can be observed not only in apple trees but also in 'Tai So' lychee, ${ }^{27}$ peach, ${ }^{28,29}$ grapefruit $^{20}$ and pear trees. ${ }^{30}$ Most of these studies, however, have only focused on how one aspect of metabolism and metabolites in the fruit is affected by canopy position, such as phenolic compounds, coloration, ${ }^{25}$ antioxidant properties, ${ }^{23,31}$ post-harvest physiology ${ }^{24}$ or the

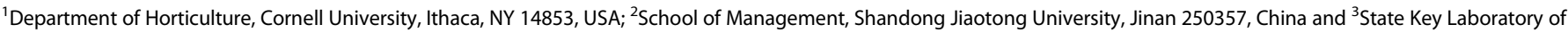
Crop Stress Biology for Arid Areas, College of Horticulture, Northwest A\&F University, Yangling 712100, China.

*These authors contributed equally to this work.

Correspondence: LL Cheng (Ic89@cornell.edu)

Received: 19 February 2014; accepted: 21 February 2014 
xanthophyll cycle and ascorbate-glutathione pathway in the peel. ${ }^{32}$ So far, no systematic effort has been made to characterize the effects of canopy position on both the primary and secondary metabolites, although fruit quality is largely determined collectively by these metabolites.

The objective of this study was to determine the levels of carbohydrates, organic acids, amino acids and phenolic compounds in relation to positions within the tree canopy to gain a full picture of the influence of canopy position on fruit quality.

\section{MATERIALS AND METHODS}

Plant material and sampling procedures

Three cultivars of apple, 'McIntosh', 'Gala' and 'Mutsu', were used in this study. 'Mclntosh' and 'Gala' produce red fruits, while 'Mutsu' produces yellow/green fruits. The 'Mclntosh' trees were on M.9 rootstocks and were planted in 1993, the 'Gala' trees were on M.26 rootstocks and were planted in 1991 and the 'Mutsu' trees were on M.9 rootstocks and were planted in 2000. The trees were grown in north-south rows at a spacing of $2.74 \times 3.05$, $2.74 \times 3.05$ and $2.44 \times 4.27 \mathrm{~m}$, respectively, at a Cornell experimental orchard near Lansing, NY, USA. All trees were trained in a central leader system and received standard pruning, fertilization, irrigation and applications of fungicides and pesticides.

On 3 and 17 September and 20 October during the normal commercial harvest for 'Gala', 'McIntosh' and 'Mutsu' trees in 2009, fruits were collected from the outside edge of the canopy (fully exposed to sunlight) as well as the interior (heavily shaded portion around the central leader). The photosynthetically active radiation $(400-700 \mathrm{~nm})$ at the inner-canopy positions was approximately $4 \%-7 \%$ of that at the outer positions, as measured by an LI-190SA quantum sensor (LI-COR Inc., Lincoln, NE, USA) at noon on a sunny day. For each cultivar, five replicates of 20 fruits each from two trees (10 fruits per tree) were taken from each canopy position. Ten fruits were used for destructive sampling, and the other 10 fruits were used for measuring flesh firmness and total soluble solids content (SSC). The peel and flesh were collected separately. Whole fruits were peeled to a thickness of approximately $1 \mathrm{~mm}$, and the remaining flesh was cut into pieces before all samples were flash-frozen in liquid nitrogen. Afterward, the samples were ground to a fine powder and stored at $-80{ }^{\circ} \mathrm{C}$ before further analysis.

\section{Firmness and SSC}

Flesh firmness was measured on opposite sides of each fruit with an EPT-1 Pressure Tester (Lake City Technical Products, Kelowna, BC, Canada) fit with an 11.1-mm-diameter probe. The SSC was determined from fresh juice with a digital refractometer (PR-100; Atago Co. Ltd., Tokyo, Japan).

\section{Sugars, organic acids and starch}

Samples of flesh or peel tissue $(0.1 \mathrm{~g})$ were extracted in $1.4 \mathrm{~mL}$ of $75 \%$ methanol, with ribitol added as an internal standard. Sugars, sugar alcohols and organic acids were measured using a 7890A/5975C GC/MS (Agilent Technologies, Palo Alto, CA, USA) according to Zhang et al. ${ }^{18}$ Following this extraction, the tissue residue was re-extracted three times with $80 \%(\mathrm{v} / \mathrm{v})$ ethanol at $80{ }^{\circ} \mathrm{C}$, and the pellet was retained for evaluating starch content. After the residue was digested overnight with 30 units of amyloglucosidase (EC 3.2.1.3) at pH 4.5, the starch content was determined enzymatically as the glucose equivalent. ${ }^{33}$

Free amino acids

Samples of the peel or flesh $(0.5 \mathrm{~g})$ were ground in $1.5 \mathrm{~mL}$ of $20 \mathrm{mM} \mathrm{HCl}$. Twenty microliters of norleucine $\left(250 \mu \mathrm{g} \mathrm{mL}^{-1}\right)$ was added as an internal standard. The extract was centrifuged at $13000 \mathrm{~g}$ for $10 \mathrm{~min}$, and the supernatant was passed through a $0.45-\mu \mathrm{m}$ syringe filter into an Eppendorf tube. Derivatization was carried out using the Waters AccQ.Fluor reagent kit (Waters, Milford, MA, USA), and the derivatized mixture was then transferred to a $100-\mu \mathrm{L}$ glass insert in an amber glass vial for high-performance liquid chromatography (HPLC) analysis. Amino acids were analyzed using an Agilent 1100 HPLC equipped with an Agilent 1200 fluorescence detector (Agilent Technologies). The analysis of free amino acids was performed as described by Zhang et al. ${ }^{4}$
Phenolic compounds

Frozen apple peel and flesh samples $(0.5 \mathrm{~g})$ were ground in $1.5 \mathrm{~mL}$ of $70 \%$ methanol containing $2 \%$ formic acid at $0-4{ }^{\circ} \mathrm{C}$ and then centrifuged at $10000 \mathrm{~g}$ for $10 \mathrm{~min}$ at $4{ }^{\circ} \mathrm{C}$. The supernatant was filtered using a $0.45-\mu \mathrm{m}$ syringe filter prior to HPLC analysis. Phenolic compounds were analyzed using an Agilent 1100 HPLC equipped with a diode array detector. Analysis followed that of Zhang et al. ${ }^{4}$

\section{Statistical analysis}

Data are presented as the means \pm s.e. of fiveve replicates. Graphs were generated using SigmaPlot 12.0 (Systat Software Inc., San Jose, CA, USA). Significant differences between inner- and outer-canopy tissues were assessed by independent-sample $t$-tests.

\section{RESULTS}

Fruit weight, firmness and SSC

For all three cultivars, fruit from the outer-canopy was heavier than that from the inner-canopy. Values for SSC were at least $1 \%$ higher for outer-canopy fruit. 'McIntosh' fruit from the outer-canopy was somewhat firmer, whereas such positional effects were not significant for either 'Gala' or 'Mutsu' fruit (Figure 1).

\section{Carbohydrates}

Starch content was higher in the peel than in the flesh, and innercanopy fruit had higher levels in all three cultivars (Figure 2). Fructose, a major soluble sugar in apples, was more abundant in the flesh. Canopy position had a significant effect on fructose accumulation: levels were higher in the flesh of outer-canopy fruit. No such effect was apparent for the peel. Regardless of cultivar, sucrose, galactose and glucose were present at moderate levels, followed in abundance by ribose and xylose. Only trace amounts of rhamnose and raffinose were detected. Overall, these sugars accumulated at higher concentrations in fruit from the outer-canopy. Contrary to

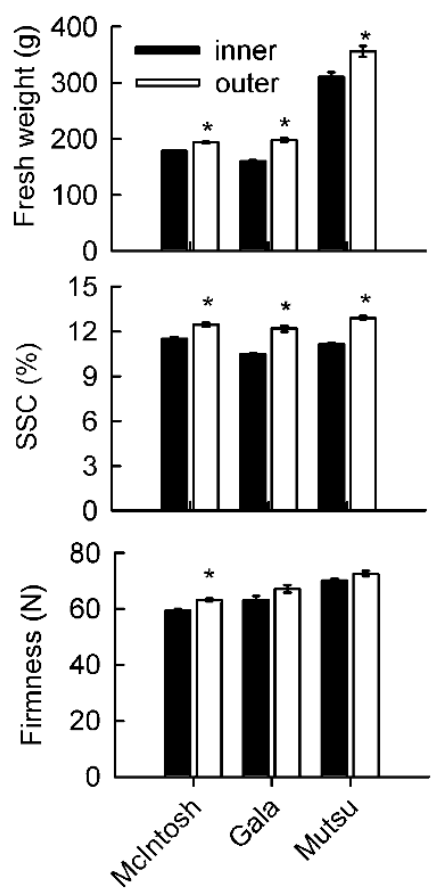

Figure 1. Effects of canopy position on fruit fresh weight, SSC and flesh firmness of three apple cultivars. Each data point is the mean \pm s.e. $(n=5)$. Significant differences between inner- and outercanopy tissues were assessed by independent-sample $t$-tests $(* p<0.05)$. 

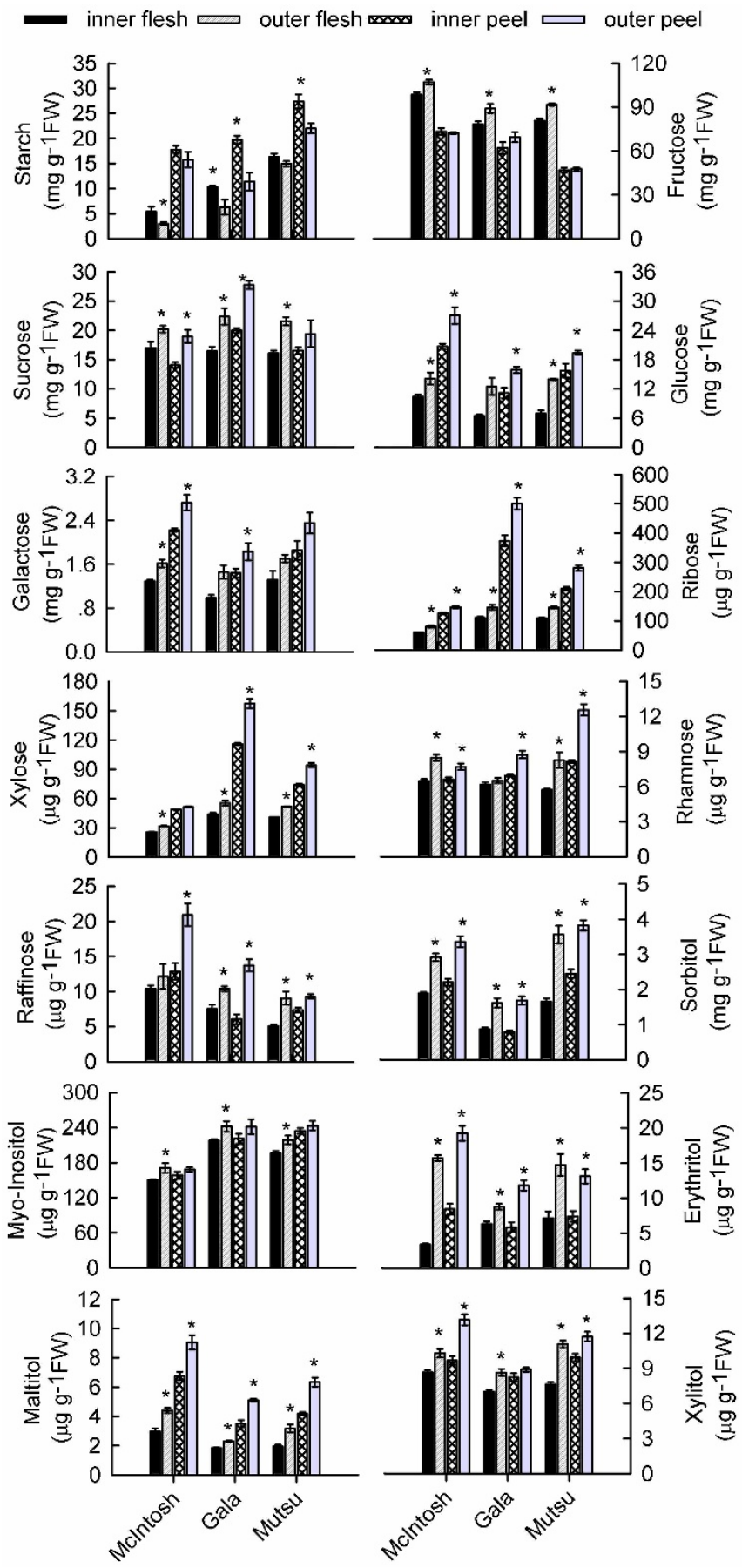

Figure 2. Effects of canopy position on carbohydrate concentrations in the peel and flesh of three apple cultivars. Each data point is the mean \pm s.e. $(n=5)$. Significant differences between inner- and outercanopy tissues were assessed by independent-sample $t$-tests $(* p<0.05)$.

the pattern of fructose accumulation, much more galactose, glucose, ribose and xylose were in the peel than in the flesh.

Sorbitol, a major sugar alcohol, was found at higher levels in the peel than in the flesh and was significantly more abundant in outercanopy fruit, followed by myo-inositol. Although the peel of outercanopy fruit had more myo-inositol than that of inner-canopy fruit, no obvious positional effects were found in the flesh samples.
Levels of maltitol, xylitol and erythritol were low for all samples, but tended to be higher in outer-canopy fruit (Figure 2).

\section{Organic acids}

The concentration of malic acid, the main organic acid in apples, was significantly higher in the peel of inner-canopy fruit than that of outer-canopy fruit from 'McIntosh' trees (Figure 3). However, the outer-canopy flesh from 'Mutsu' trees had a higher concentration of malic acid than that of the inner-canopy flesh. Quinic acid in 'Mclntosh' fruit accumulated at higher concentrations in outercanopy flesh and inner-canopy peels. For the other two cultivars, positional effects were found only in 'Mutsu' peels, in which outercanopy peels had much higher levels of quinic acid than innercanopy peels. Although the citric acid level was higher in the peels of inner-canopy fruit from the 'Mutsu' cultivar, no such differences were apparent from either the 'McIntosh' or 'Gala' cultivars. Canopy position had no significant effect on ascorbic acid (AsA) concentrations in the flesh from any of the cultivars. However, AsA concentrations from peel samples were approximately 1.6-1.9 times higher in fruit from the outer-canopy (Figure 3). Succinic acid was present at only very low levels throughout the fruit, and it tended to be more concentrated in peel and flesh from the outer-canopy. In 'McIntosh' fruit, fumaric and maleic acids showed similar responses, with both being more abundant in outer-canopy flesh and innercanopy peels. For 'Gala' fruit, differences in these acids were not obvious in either the peel or the flesh. In 'Mutsu' fruit, both acids accumulated at higher concentrations in the outer-canopy flesh, though position had no significant effect on their levels in the peel.

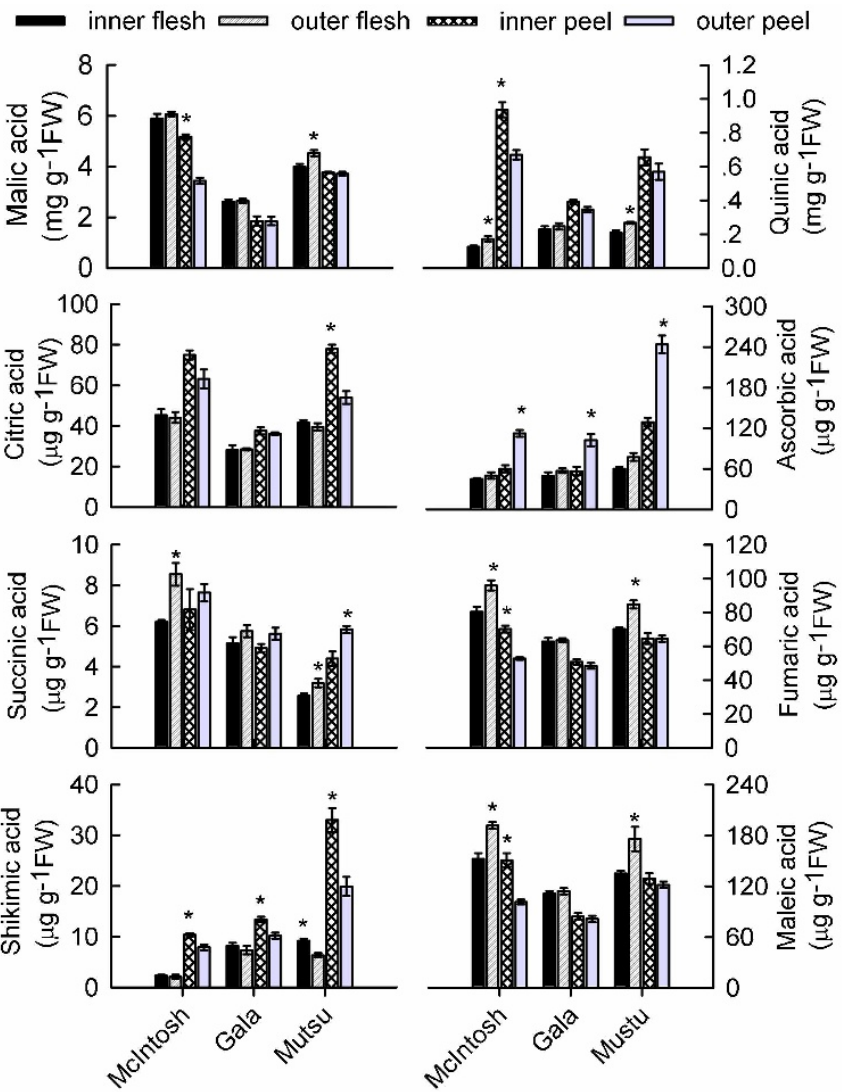

Figure 3. Effects of canopy position on concentrations of organic acids in the peel and flesh of three apple cultivars. Each data point is the mean \pm s.e. $(n=5)$. Significant differences between inner- and outer-canopy tissues were assessed by independent-sample $t$-tests $(* p<0.05)$. 
For all three cultivars, the concentration of shikimic acid was higher in the peel of inner-canopy fruit, but only 'Mutsu' showed an obvious positional effect in the flesh, in which the level was higher for inner-canopy fruit. Overall, the distribution of organic acids in 'Gala' fruit was not as sensitive to canopy position, with only AsA and shikimic acid showing visible differences in the peel.

\section{Amino acids}

Apples primarily contain acid aliphatic amino acids and their amides, including Asp, Asn, Glu and Gln. Except for the levels of Asp and Gln in 'Mutsu' flesh and of Gln in 'Gala' peels, the position within the canopy significantly affected the levels of these amino acids (Figure 4). This was most apparent for Asn in 'Mclntosh' fruit, which displayed values of $563.0 \pm 45.7 \mu^{-1} \mathrm{gW}$ (inner) vs. $75.1 \pm 2.6 \mu \mathrm{g} \mathrm{g}^{-1} \mathrm{FW}$ (outer) in the flesh and $149.0 \pm 3.0 \mu \mathrm{g} \mathrm{g}^{-1}$ FW (inner) vs. $26.0 \pm 4.8 \mu \mathrm{g} \mathrm{g}^{-1} \mathrm{FW}$ (outer) in the peel. The levels of Asp, Glu and Gln were 3.5, 1.8 and 3.1 times higher, respectively, in the flesh of 'Mclntosh' fruits from the inner-canopy; for the peel, the respective fold-increases were 2.7, 1.9 and 2.8. In 'Gala' fruit, the concentrations of Asn, Asp, Glu and Gln were 7.0, 1.5, 1.5 and 2.1 time greater, respectively, in the flesh and 1.7, 1.5, 1.4 and 1.0 times greater in the peels from the inner-canopy. In 'Mutsu' fruit, concentrations were 2.4 (Asn), 1.2 (Asp), 1.0 (Glu) and 0.9 (Gln) times higher in inner-canopy flesh, and 2.2 (Asn), 1.8 (Asp), 1.5 (Glu) and 1.2 (Gln) times higher in inner-canopy peels.

Only small to moderate amounts of Ser, Met and Thr, the amino acids with a hydroxyl or sulfenyl group, were present in the sampled tissues. Both Ser and Met were significantly more abundant in inner-canopy fruit from all three cultivars. In 'McIntosh' fruit, Thr concentrations were not affected by canopy position, whereas Thr levels were higher in 'Gala' and 'Mutsu' fruit from the outercanopy (Figure 4).

The neutral aliphatic amino acids examined here included Ala, Val, Gly, Ile and Leu. For all three cultivars, Ala and Val levels were significantly higher in the inner-canopy fruit, with the exception of 'Gala' peels, in which no Val concentration differences were detected (Figure 4). More Gly accumulated in the outer-canopy peels of 'Gala' and 'Mutsu' fruit, whereas no differences were observed in the flesh samples. The Gly concentrations in 'Mclntosh' fruit did not differ between inner- and outer-canopy fruit. Levels of Ile and Leu were very low in all cultivars (Figure 4).

The basic aliphatic amino acids showed inconsistent responses to canopy position, with Lys concentrations being higher in the outer-canopy peels from all three cultivars and in the flesh from inner-canopy 'Mclntosh' fruit. No significant differences between canopy positions were found for flesh samples from 'Gala' and 'Mutsu' fruits. The flesh of 'Mclntosh' and 'Gala' fruits from the inner-canopy had greater concentrations of Arg, but flesh from 'Mutsu' fruit was insensitive to positional effects (Figure 4). There was no significant effect of canopy position on Arg concentrations in fruit peels of the cultivars except in 'Mclntosh' fruit, for which more Arg accumulated in inner-canopy flesh. Fruit from outercanopy of all three cultivars had higher levels of His compared to inner canopy fruit, except in the flesh of 'Mclntosh' fruit, which was not significantly different between the two positions.

For the aromatic amino acids, Phe was more abundant in the inner-canopy fruit of each cultivar. Tyr had higher concentrations in the 'Mclntosh' flesh and the 'Mutsu' peel of outer-canopy fruits. No differences were observed in 'Gala' fruit from the inner- and outer-canopy (Figure 4).

Canopy position did not affect the distribution of Pro in fruits from the three cultivars, with the exception that much more Pro was concentrated in 'Mclntosh' flesh from the inner-canopy. For 'McIntosh' and 'Gala' fruits, more $\gamma$-aminobutyric acid was found in the inner-canopy flesh, and none was detected in the peels; no


Figure 4. Effects of canopy position on concentrations of free amino acids in the peel and flesh of three apple cultivars. Each data point is mean \pm s.e. $(n=5)$. Significant differences between inner- and outercanopy tissues were assessed by independent-sample $t$-tests $\left({ }^{*} p<0.05\right)$ 
obvious differences were found in 'Mutsu' fruit. The Orn concentration was minimal in all tissues from the three cultivars (Figure 4).

Phenolic compounds

Chlorogenic acid was more concentrated in the outer-canopy fruit. Regardless of cultivar or tissue type, chlorogenic acid concentrations were the highest of all the phenolic acids measured here. The syringic acid concentration was not significantly influenced by location within the canopy, except that more was detected in 'Gala' peels from the outer-canopy. Gallic acid, gentisic acid and caffeic acid were mainly located in the peel, especially in fruits collected from the outer-canopy (Figure 5).

Higher levels of the four flavan-3-ols were found in the peels compared to the flesh of all cultivars. For 'McIntosh' fruit, both tissue types showed higher concentrations of catechin, epicatechin, and procyanidin B2 in fruit from the outer-canopy; the concentration of procyanidin $\mathrm{B} 1$ in the peel remained the same, regardless of position. More procyanidin B1 and B2 were found in 'Gala' fruit from the outer-canopy, and the catechin and epicatechin levels were also higher in those peels. For 'Mutsu' fruit, the levels of catechin and procyanidin B2 were higher in flesh from the outer-canopy, whereas levels of epicatechin and procyanidin B1 were higher in peels from the outer-canopy (Figure 5).

Phloridzin, a phenolic compound unique to apples, was not sensitive to position in 'Gala' and 'Mutsu' fruits. However, it accumulated more in 'Mclntosh' fruit from the outer-canopy. For all three cultivars, much more phloridzin was detected in the peel than in the flesh (Figure 5).

Canopy position also strongly influenced the levels of six flavonols, which were mainly concentrated in the peel and only detected in minute amounts in the flesh. The levels of hyperin (quercetin-3galactoside), rutin (quercetin-3-rutinoside), isoquercitrin (quercetin-3-glucoside), reynoutrin (quercetin-3-xyloside), avicularin (quercetin-3-arabinoside) and quercitrin (quercetin-3-rhamnoside) were 25.1, 20.6, 6.4, 5.9, 5.8 and 4.2 times higher, respectively, in 'Mclntosh' peels from the outer-canopy compared to the innercanopy. The respective fold-increases in flavonols in the outercanopy peels were 9.7, 16.1, 3.6, 4.0, 3.3 and 3.6 in 'Gala' fruit, and $18.5,22.0,16.1,14.3,4.1$ and 4.2 in 'Mutsu' fruit (Figure 5).

Visible differences in peel coloration between the inner- and outer-canopy fruits resulted from their accumulations of cyanidin3-glycosides. In 'Mclntosh' fruit, peels from the outer-canopy had over 10 times more cyanidin-3-galactoside than those from the inner-canopy $\left(756.8 \pm 64.1{\mu \mathrm{g} \mathrm{g}^{-1}} \mathrm{FW}\right.$ vs. $\left.73.7 \pm 10.2 \mu \mathrm{g} \mathrm{g}^{-1} \mathrm{FW}\right)$. In 'Gala' fruit, the concentration increased by approximately fourfold (923.4 $\pm 22.5 \mu \mathrm{g} \mathrm{g}^{-1} \mathrm{FW}$ vs. 230.2 $\left.\pm 9.8 \mu \mathrm{g} \mathrm{g}^{-1} \mathrm{FW}\right)$. The greenskinned 'Mutsu' fruit contained only $12.3 \pm 1.07 \mu \mathrm{g}$ of cyanidin-3galactoside per gram FW in samples from the outer-canopy, and none in samples from the inner-canopy. The levels of cyanidin-3glucoside were minimal for all three cultivars (Figure 5).

\section{DISCUSSION}

The position within the tree canopy has a significant influence on the concentrations of both primary and secondary metabolites in apples. Here, fruit collected from the outer-canopy was heavier and had a higher soluble solids content (Figure 1). These findings are consistent with those reported for the 'Aroma' apple ${ }^{24}$ as well as pear $^{30}$ and grapefruit. ${ }^{20}$ This suggests that fruit in the outer-portions of the canopy benefit from better light exposure because leaves in those positions have greater photosynthetic capacity. ${ }^{18}$ The difference in the carbon supply to fruit as a result of canopy light exposure may also explain why our inner-canopy fruit had lower levels of sorbitol and sucrose (Figure 2) because, in apple, both sorbitol and sucrose are translocated from the source leaves to the fruit. Consequently, the levels of fructose in the flesh and glucose in general were lower in the inner-canopy fruit. These fruits
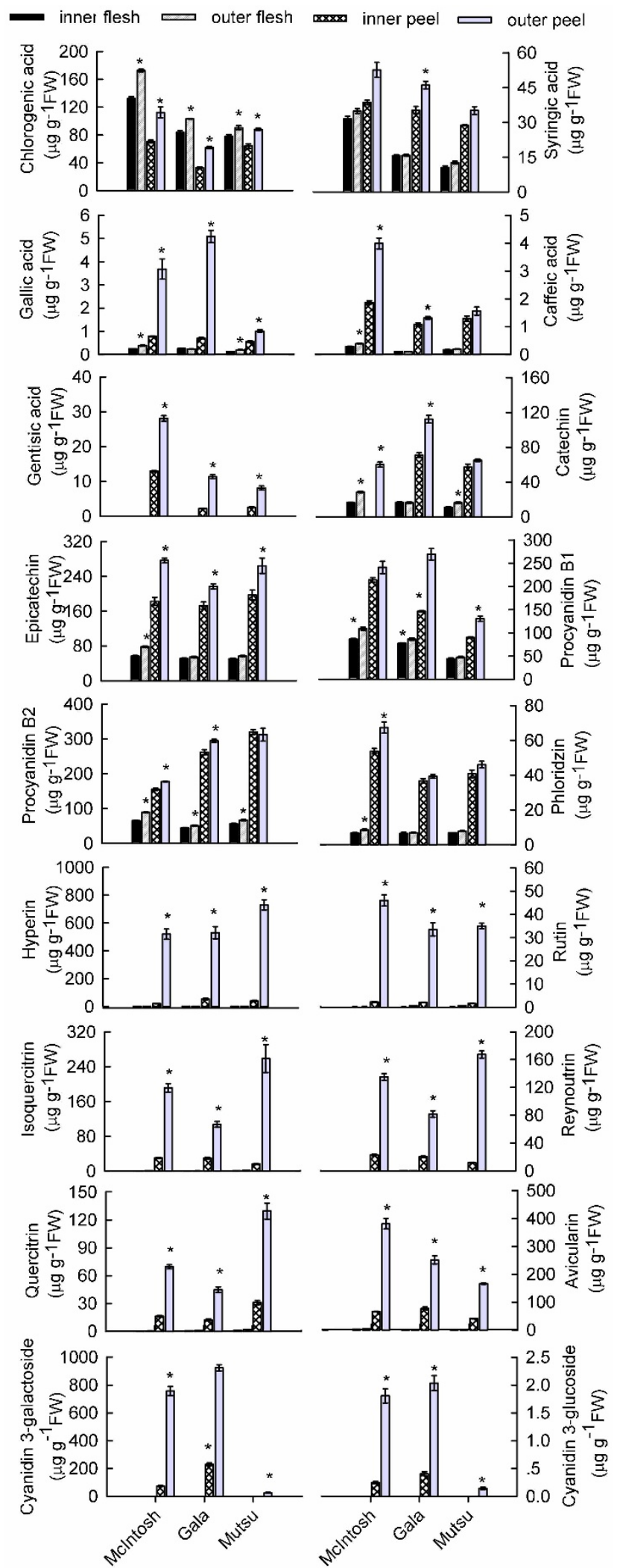

Figure 5. Effects of canopy position on concentrations of phenolic compounds in the peel and flesh of three apple cultivars. Each data point is mean \pm s.e. $(n=5)$. Significant differences between inner- and outer-canopy tissues were assessed by independent-sample $t$-tests $(* p<0.05)$. 
had more starch, implying that maturation is delayed in locations deeper within the canopy, where there is less light available. Malic acid levels were not significantly affected by position in the 'Gala' cultivar (Figure 3), confirming a previous report ${ }^{19}$ that acidity does not differ significantly within the canopy. However, Nilsson and Gustavsson ${ }^{24}$ have shown that the outer-canopy fruits have a somewhat lower titratable acidity. As demonstrated by Li et al. ${ }^{34}$, light affects AsA biosynthesis and recycling in the peel and the leaves, but not in the flesh. We also found that the AsA concentration was approximately 1.6 to 1.9 times higher in the peel of fruit from the outer-canopy, whereas no significant difference was detected in the concentration in the flesh between the inner- and outer-canopy (Figure 3).

Our data showed that, regardless of tissue type, amino acids, especially Asp, Asn, Glu and Ser, were more abundant in the inner-canopy fruit (Figure 4). However, it is not yet clear why these fruits have higher amino-acid levels. Considering that the levels of all amino acids except Pro decrease with fruit development, ${ }^{4}$ delayed fruit maturity may have contributed to the higher levels of amino acids in inner-canopy fruit. Another possibility is that inner canopy fruit maintains a lower level of metabolism because of the cooler temperature and lower light levels, so that fewer proteins are needed, leading to a higher accumulation of amino acids. Regardless of the exact cause, the high amino-acid levels in the inner-canopy fruit may indicate poor eating and storage quality, as both apples and potato tubers grown under high nitrogen supply are characterized by high amino-acid levels and storage quality. ${ }^{35,36}$

By contrast, the levels of phenolic compounds in both the peel and flesh were significantly higher for the outer-canopy fruit compared to the inner-canopy fruit (Figure 5). The association was most pronounced between fruit location and the levels of flavonols and anthocyanins. Our results are consistent with those of Awad et al. ${ }^{17,37}$ and Jakopic et al., ${ }^{22}$ who showed that anthocyanin and flavonols are most abundant in fruits from the top of the tree, followed by those from the side branches, with the lowest amounts measured from interior canopy fruits. We also noted that the concentrations of catechins, chlorogenic acid and phloridzin were higher in both the peel and the flesh of outer-canopy fruit. This is in contrast to previous reports that levels of these constituents in apple peels are independent of light exposure. ${ }^{17,22,37}$ Nevertheless, Chen et al..$^{38}$ have determined, using bagged fruit, that accumulation of these compounds can be affected by light levels under such conditions. Furthermore, they have shown that the concentration of each type of flavanol is significantly influenced by either cultivar or shading treatment and that there is an interaction between those two factors. Thus, some of our data may be inconsistent with previous results because the positional effects may vary among cultivars or under different microenvironments.

Phenolic compounds are primarily synthesized through the pentose phosphate, shikimate, and phenylpropanoid pathways. ${ }^{39}$ Therefore, the higher shikimate levels measured in the innercanopy fruit (Figure 3) may be a result of the inhibition of the synthesis of phenolic compounds or other secondary metabolites.

In conclusion, canopy position has a significant effect on fruit size and color and on concentrations of both primary and secondary metabolites. Fruit from the outer-canopy has a higher average fruit weight and a higher soluble solids content than fruit from the innercanopy. Both the flesh and peel of outer-canopy fruit have higher soluble carbohydrates, anthocyanins, flavonols and other phenolic compounds, but lower amino acids than those of inner-canopy fruit. Some of these effects, such as phenolic compounds in the peel, are most likely direct responses to light availability, whereas others may be indirect responses to the supply of carbohydrates to the fruit and their metabolism. These results clearly demonstrate the importance of light exposure on apple fruit quality and of canopy management to ensure better light exposure.

\section{CONFLICTS OF INTEREST}

The authors declare no conflicts of interest.

\section{ACKNOWLEDGMENTS}

This work was supported by the Cornell Agricultural Experiment Station and New York Apple Research and Development Program. We thank Mr Richard Raba and Dr. Fangfang Ma for technical assistance with HPLC and GC/MS and Priscilla Licht for editorial assistance.

\section{REFERENCES}

1 Hyson DA. A comprehensive review of apples and apple components and their relationship to human health. Adv Nutr 2011; 2: 408-420.

2 Awad MA, de Jager A. Influences of air and controlled atmosphere storage on the concentration of potentially healthful phenolics in apples and other fruits. Postharvest Biol Technol 2003; 27: 53-58.

3 Hecke K, Herbinger K, Veberič R et al. Sugar-, acid-and phenol contents in apple cultivars from organic and integrated fruit cultivation. Eur J Clin Nutr 2006; 60: 1136-1140.

4 Zhang YZ, Li PM, Cheng LL. Developmental changes of carbohydrates, organic acids, amino acids, and phenolic compounds in 'Honeycrisp' apple flesh. Food Chem 2010; 123: 1013-1018.

5 Berüter J. Carbohydrate metabolism in two apple genotypes that differ in malate accumulation. J Plant Physiol 2004; 161: 1011-1029.

6 Burroughs L. The amino-acids of apple juices and ciders. J Sci Food Agric 1957; 8 122-131.

7 Gomis DB, Lobo AM, Alvarez MD et al. Determination of amino acids in apple extracts by high performance liquid chromatography. Chromatographia 1990; 29: $155-160$.

8 Treutter D. Biosynthesis of phenolic compounds and its regulation in apple. Plant Growth Regul 2001; 34: 71-89.

9 Tsao R, Yang R, Xie S et al. Which polyphenolic compounds contribute to the total antioxidant activities of apple? J Agric Food Chem 2005; 53: 4989-4995.

10 Feng FJ, Li MJ, Ma FW, Cheng LL. Phenylpropanoid metabolites and expression of key genes involved in anthocyanin biosynthesis in the shaded peel of apple fruit in response to sun exposure. Plant Physiol Biochem 2013; 69: 54-61.

11 Volz R, McGhie T. Genetic variability in apple fruit polyphenol composition in Malus $\times$ domestica and Malus sieversii germplasm grown in New Zealand. J Agric Food Chem 2011; 59: 11509-11521.

12 Feng FJ, Li MJ, Ma FW, Cheng LL. The effects of bagging and debagging on external fruit quality, metabolites, and the expression of anthocyanin biosynthetic genes in 'Jonagold' apple (Malus domestica Borkh.). Sci Hort 2014; 165: 123-131.

13 Lata B. Relationship between apple peel and the whole fruit antioxidant content: year and cultivar variation. J Agric Food Chem 2007; 55: 663-671.

14 Wolfe KL, Liu RH. Apple peels as a value-added food ingredient. J Agric Food Chem 2003; 51: 1676-1683.

15 Lata B, Trampczynska A, Paczesna J. Cultivar variation in apple peel and whole fruit phenolic composition. Sci Hort 2009; 121: 176-181.

16 Fromm M, Bayha S, Carle R et al. Characterization and quantitation of low- and high-molecular weight phenolic compounds in apple seeds. J Agric Food Chem 2012; 60: 1232-1242.

17 Awad MA, Wagenmakers PS, de Jager A. Effects of light on flavonoid and chlorogenic acid levels in the skin of 'Jonagold' apples. Sci Hort 2001; 88: 289-298.

18 Barritt B, Rom C, Guelich K et al. Canopy position and light effects on spur, leaf, and fruit characteristics of delicious apple. HortScience 1987; 22: 402-405.

19 Krishnaprakash MS, Aravindaprasad B, Krishnaprasad CA et al. Effect of apple position on the tree on maturity and quality. J Hort Sci 1983; 58: 31-36.

20 Syvertsen J, Albrigo L. Some effects of grapefruit tree canopy position on microclimate, water relations, fruit yield, and juice quality. J Am Soc Hort Sci 1980; 105: 454-459.

21 Tustin D, Hirst P, Warrington I. Influence of orientation and position of fruiting laterals on canopy light penetration, yield, and fruit quality of 'Granny Smith' apple. J Am Soc Hort Sci 1988; 113: 693-699.

22 Jakopic J, Stampar F, Veberic R. The influence of exposure to light on the phenolic content of 'Fuji' apple. Sci Hort 2009; 123: 234-239.

23 Drogoudi PD, Pantelidis G. Effects of position on canopy and harvest time on fruit physico-chemical and antioxidant properties in different apple cultivars. Sci Hort 2011; 129: 752-760.

24 Nilsson T, Gustavsson KE. Postharvest physiology of 'Aroma' apples in relation to position on the tree. Postharvest Biol Technol 2007; 43: 36-46.

25 Unuk T, Tijskens L, Germšek B et al. Effect of location in the canopy on the colour development of three apple cultivars during growth. J Sci Food Agric 2012; 92 2450-2458. 
26 Hagen SF, Borge Gl, Bengtsson GB et al. Phenolic contents and other health and sensory related properties of apple fruit (Malus $\times$ domestica Borkh., cv. Aroma): effect of postharvest UV-B irradiation. Postharvest Biol Tech 2007; 45: 1-10.

27 Tyas JA, Hofman PJ, Underhill SJ et al. Fruit canopy position and panicle bagging affects yield and quality of 'Tai So' lychee. Sci Hort 1998; 72: 203-213.

28 Bible BB, Singha S. Canopy position influences CIELAB coordinates of peach color. HortScience 1993; 28: 992-993.

29 Génard M, Bruchou C. Multivariate analysis of within-tree factors accounting for the variation of peach fruit quality. Sci Hort 1992; 52: 37-51.

30 Sanchez EE, Righetti TL. Tree nitrogen status and leaf canopy position influence postharvest nitrogen accumulation and efflux from pear leaves. J Am Soc Hort Sci 1990; 115: 934-937.

31 Vieira F, Borges G, Copetti C et al. Activity and contents of polyphenolic antioxidants in the whole fruit, flesh and peel of three apple cultivars. Arch Latinoam Nutr 2009; 59: 101-106.

32 Ma FW, Cheng LL. The sun-exposed peel of apple fruit has higher xanthophyl cycle-dependent thermal dissipation and antioxidants of the ascorbateglutathione pathway than the shaded peel. Plant Sci 2003; 165: 819-827.

33 Chen LS, Cheng LL. Carbon assimilationg and carbohydrate metabolism of 'Concord' grape (Vitis labrusca L.) leaves in response to nitrogen supply. J Am Soc Hort Sci 2003; 128: 754-760.
34 Li MJ, Ma FW, Shang PF et al. Influence of light on ascorbate formation and metabolism in apple fruits. Planta 2009; 230: 39-51.

35 Wang HC, Ma FF, Cheng LL. Nitrogen metabolism of 'Gala' apple fruit in response to nitrogen supply. HortScience 2010; 45: S150.

36 de Wilde TB, de Meulenaer F, Mestdagh $\mathrm{Y}$ et al. Influence of fertilization on acrylamide formation during frying of potatoes harvested in 2003. J Agric Food Chem 2006; 54: 404-408.

37 Awad MA, de Jager A, van Westing LM. Flavonoid and chlorogenic acid levels in apple fruit: characterisation of variation. Sci Hort 2000; 83: 249-263.

38 Chen CS, Zhang D, Wang YQ et al. Effects of fruit bagging on the contents of phenolic compounds in the peel and flesh of 'Golden Delicious', 'Red Delicious', and 'Royal Gala' apples. Sci Hort 2012; 142: 68-73.

39 Randhir R, Lin YT, Shetty K. Stimulation of phenolics, antioxidant and antimicrobial activities in dark germinated mung bean sprouts in response to peptide and phytochemical elicitors. Process Biochem 2004; 39: 637-646.

(c) (i) (2) This work is licensed under a Creative Commons AttributionBY NG SA NonCommercial-ShareAlike 3.0 Unported License. To view a copy of this license, visit http://creativecommons.org/licenses/by-nc-sa/3.0 